\title{
Quantitative precipitation forecasting in the Alps: The advances achieved by the Mesoscale Alpine Programme
}

\author{
Evelyne Richard, ${ }^{\mathrm{a} *}$ Andrea Buzzi ${ }^{\mathrm{b}}$ and Günther Zängl ${ }^{\mathrm{c}}$ \\ ${ }^{a}$ Laboratoire d'Aérologie, CNRS/UPS, Toulouse, France \\ b ISAC-CNR, Bologna, Italy \\ ${ }^{\mathrm{c}}$ Meteorologisches Institut der Universität München, Germany
}

\begin{abstract}
The improvement of Quantitative Precipitation Forecasting (QPF) in mountainous regions was a major supporting objective of the Mesoscale Alpine Programme (MAP) project P1 devoted to the study of orographic precipitation. This paper reviews the main MAP-related achievements regarding QPF improvement and highlights the MAP impact on developing QPF research and planning future operational strategies. Recent results based on MAP case-studies, on data analysis and assimilation, on quantification of model uncertainties, and on model intercomparison and verification substantiate the progress made in recent years in improving model performance in relation to short-range, high-resolution forecasting in complex topography regions, well represented by the European Alps. Copyright (C) 2007 Royal Meteorological Society
\end{abstract}

KEY WORDS high-resolution numerical modelling; orographically influenced precipitation

\section{Introduction}

While many aspects of numerical weather forecasting have made great advances during the last two decades, progress in quantitative precipitation forecasting (QPF) has been comparatively slow (e.g. Fritsch et al., 1998). One explanation is that precipitation is an end product of a complex chain of physical processes, including upward vertical air motion, condensation, formation of precipitation through microphysical conversion processes, and fallout and downstream advection of precipitation particles. These processes extend over an extremely large range of length-scales, from synoptic-scale lifting $(\sim 1000 \mathrm{~km})$ to the scale of cloud droplets $(\sim 10 \mu \mathrm{m})$. The microphysical processes cannot be directly resolved in an atmospheric model and thus need to be parametrized, introducing a wide spectrum of model uncertainties. Moreover, even the dynamical part of the scale range, reaching down to $\sim 100 \mathrm{~m}$ for convective motions and a few $\mathrm{cm}$ for important turbulent motions within clouds, is only partly resolved in current forecasting models. In this range of scales, the atmospheric flow is subject to important dynamical instability processes, namely baroclinic instability, around $1000 \mathrm{~km}$, and the moist conditional instability, around $1-10 \mathrm{~km}$. The forecast error growth at such different scales is mainly a manifestation of the aforementioned instabilities. The relatively coarse resolution of global, but also regional limited-area,

\footnotetext{
* Correspondence to: Evelyne Richard, Laboratoire d'Aérologie, 14 avenue Edouard Belin, 31400 Toulouse, France.

E-mail: Evelyne.Richard@aero.obs-mip.fr
}

models entails the long-standing problem of parametrizing cumulus convection, which is known to add further uncertainties to QPF. Another crucial aspect is the large sensitivity of precipitation to uncertainties in the initial and, for limited-area models, boundary conditions. On the other hand, there is a growing public interest in accurate precipitation forecasts because of the large impact of precipitation on agriculture, outdoor activities, traffic, hydroelectric power generation, or flooding preparedness.

Reliable precipitation forecasts are particularly important in mountainous regions because of the increased likelihood of heavy precipitation, entailing the risk of flash floods over sloping terrain. However, the presence of mountainous orography is very demanding to the numerics and physical parametrizations of a numerical model, implying that a fine model resolution alone is not sufficient to obtain reliable forecasts. Thus, it was natural to define orographic precipitation as the subject of project P1 of the Mesoscale Alpine Programme (MAP), which culminated with a Special Observing Period (SOP), held in the European Alps in autumn 1999 (Bougeault et al., 2001; Volkert and Gutermann, 2007). The target area selected for P1 was the Swiss/Italian Lago Maggiore region, which is known to be frequently affected by heavy precipitation in autumn. The primary goals of $\mathrm{P} 1$ were (i) to improve the dynamical understanding of orographic precipitation enhancement, (ii) to investigate the related cloud microphysical processes, and (iii) to provide a dataset of unprecedented spatial and temporal resolution for the validation of high-resolution numerical 
weather prediction models. Weather conditions permitted these goals to be fully reached, with nearly $40 \%$ of the 70 SOP days being relevant for QPF. Compared to other recent field experiments dealing with orographic precipitation (see below), MAP exhibits some special features that make it unique for QPF purposes. The MAP SOP was the first major European field experiment for which quasi-operational forecasts were made with a highresolution $(3 \mathrm{~km})$ non-hydrostatic model working without parametrization for cumulus convection. The forecasts were obtained with the numerically innovative and efficient Canadian MC2 model (Benoit et al., 1997). At the same time, operational regional and global weather forecasts were available from several numerical weather prediction centres (Table I, models with an asterisk), providing an excellent opportunity to assess the performance of MC2 in comparison with lower-resolution hydrostatic models using parametrized convection. The operational forecasts also provided a reference for case-study simulations conducted after the MAP SOP with high-resolution non-hydrostatic models (Table I). Some of these models, such as the fifth-generation PSU/NCAR mesoscale model MM5 (Dudhia, 1993) or the French MESO-NH (Lafore et al., 1998), are primarily used for research purposes, whereas others have become operational, e.g. the German Lokal-Modell (LM, Doms and Schättler, 2002), or are in a pre-operational testing stage, like the Italian model MOLOCH (Drofa and Malguzzi, 2004; Zampieri et al., 2005). Another unique feature of the MAP SOP is the availability of a complete re-analysis, conducted at ECMWF and making use of a large fraction of the special data collected during the SOP (Keil and Cardinali, 2004). Thus, MAP also provides a good opportunity for assessing the impact of the quality of the largescale analysis on the results of high-resolution simulations.

MAP was preceded by a number of other field experiments addressing the problem of mesoscale orographic flows and orographic precipitation, including microphysical aspects. Starting from the 1990s, the SALPEX project (New Zealand Southern Alps Experiment, Ryan and Gayet, 1996) investigated dynamical and precipitation processes associated with the flow over the Southern Alps (Revell et al., 2002). The COAST campaign (Coastal Observation and Simulation with Topography, Bond et al., 1997), conducted in the area of the United States close to the Pacific coast, utilized for the first time an airborne Doppler radar to monitor wind flows over the Olympic Mountains. Simulations with $3 \mathrm{~km}$ resolution using MM5 were verified in the same area (Colle et al., 1999). High-resolution (4 km) real-time forecasts using MM5 were initiated in 1998 (Mass and Kuo, 1998) and the results were reported in Colle et al. (2001) and Mass et al. (2002). Meanwhile, a number of field projects were designed and conducted, either immediately before or after MAP, to better understand precipitation over complex terrain, such as CALJET (California Land-falling Jets experiment, Ralph et al., 1999), PACJET (Pacific Land-falling Jets experiment, Neiman et al., 2002), IPEX (Intermountain Precipitation Experiment, Schultz et al., 2002) and IMPROVE (Improvement of Microphysical Parameterization through Observational Verification Experiment, Stoelinga et al., 2003). In CALJET, orographically modified precipitation was studied in connection with the 'landfall' of oceanic cyclones and associated fronts (Kingsmill et al., 2006). The dynamical and microphysical data obtained in IPEX allowed detailed observational and numerical studies of precipitation over and upstream of the Wasatch Mountains in Utah (Colle et al., 2005; Shafer et al., 2006). IPEX and, to a larger extent, IMPROVE were more specifically targeted than MAP-P1 at measuring cloud microphysical properties related to orographic precipitation. However, some of the radar and aircraft observations of IMPROVE-2, obtained in the Oregon Cascade Mountains, were compared with those of MAP for what concerns the microphysical and turbulence properties in updraught cells enhancing precipitation in the weakly stable and sheared upslope flow (Houze and Medina, 2005; Medina et al., 2005; Rotunno and Houze, 2007).

In 2007, another major field experiment focusing on summertime convection in mountainous terrain will be conducted in south-western Germany (COPS, Convective

Table I. Characteristics of the different models used in this study.

\begin{tabular}{llcll}
\hline Model & Equation system & Resolution $(\mathrm{km})$ & Driving model & Developing centre \\
\hline ECMWF $^{*}$ & Hydrostatic & $40-60$ & - & ECMWF \\
ARPEGE* $^{*}$ & Hydrostatic & 30 & - & Météo-France \\
ALADIN $^{*}$ & Hydrostatic & $10-15$ & ARPEGE & Météo-France \\
SM$^{*}$ & Hydrostatic & 14 & EM & MeteoSwiss \\
BOLAM $^{*}$ & Hydrostatic & $30-7$ & ECMWF & ISAC (Italy) \\
LM$^{*}$ & Compressible & 7 & GME & DWD (Germany) \\
MC2 & Compressible & 3 & SM & Environment Canada \\
MM5* & Compressible & $50-1$ & ECMWF or NCEP & NCAR/PSU (USA) \\
MESO-NH & Anelastic & $50-1$ & ECMWF or ARPEGE & Météo-France/LA \\
MOLOCH & Compressible & 2 & BOLAM & ISAC (Italy) \\
WRF & Compressible & $18-2$ & ECMWF & NCAR/NOAA (USA) \\
\hline
\end{tabular}

\footnotetext{
* Run operationally during MAP.
} 
and Orographically-induced Precipitation Study). This sequence of QPF-related field experiments underlines the high priority given to QPF in the scientific community and highlights the need to exchange research results between different working groups.

For a deeper discussion of the scientific results concerning orographic precipitation obtained in MAP, in comparison also with other similar field experiments, the reader is referred to the paper by Rotunno and Houze (2007). Progress in numerical models and forecasting should be, and is, in principle, related to improvements in observations and understanding of the basic processes. However, due to the a number of reasons (for example, difficulties in observing, simulating and/or parametrizing small-scale processes like those related to convection, microphysics and turbulence; difficulties in obtaining accurate precipitation measurements except for very limited areas and time spans; problems in assimilation of mesoscale fields, etc.), modelling advances often proceed at their own pace and along their own guidelines and therefore are worthy of specific investigation and discussion. Hence, the main goal of this paper is to summarize how MAP helped to improve QPF in mountainous terrain. Section 2 reviews the studies carried out to verify the simulated precipitation. Model improvements triggered by MAP are described in Section 3. The impact of the initial conditions and predictability issues are discussed in Sections 4 and 5 respectively. In addition, results of a new model intercomparison project are presented in Section 6. Conclusions and the current outlook are given in Section 7.

\section{Verification of simulated precipitation}

We first summarize findings from studies which cover the full SOP period (from 7 September to 15 November 1999) and afterwards review the main results of case studies based on different Intensive Observation Periods (IOPs).

\subsection{Studies covering the entire SOP}

The community has put much effort into the evaluation of precipitation forecasts. Some of the studies have aimed at a systematic evaluation over the whole SOP. Keil and Cardinali (2004) compared ECMWF $24 \mathrm{~h}$ areal precipitation forecasts with the observations over the entire catchment of the river Po and its tributaries. The agreement was remarkable for the operational runs and was even slightly improved for the repeated integrations based upon the MAP re-analyses mentioned above. Figure 1 illustrates the quality of the results. Events of interest for precipitation studies are labelled according to the number of the IOP during which they occurred. Both peak values and timing of the precipitating events are well captured.

However, the real challenge for QPF was the assessment of higher-resolution precipitation forecasts. In a

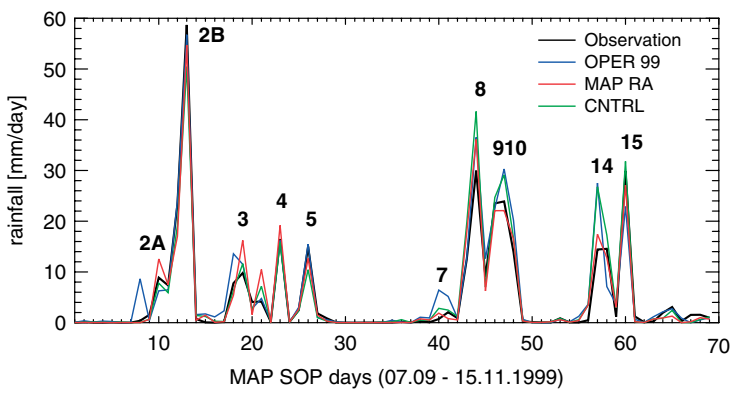

Figure 1. Time series of daily precipitation averaged over the Po catchment. Comparison between observations, operational and different experimental ECMWF forecasts initialized at 12 UTC and for a forecast range of +18 to $+42 \mathrm{~h}$ (from Keil and Cardinali, 2004)

very pioneering experiment in Europe, the Canadian MC2 model (Benoit et al., 1997) was run operationally during the whole MAP SOP at a resolution of $3 \mathrm{~km}$ over the entire Alpine domain. The main goal was to provide high-resolution forecasts in support of the field phase but also to gain early experience with a next-generation non-hydrostatic model. Benoit et al. (2002) show that the MC2 real-time forecasts captured the timing and the structure of the precipitation events quite well but underpredicted the magnitude of the precipitation by a factor of 2. The systematic underprediction was subsequently attributed to an error in the cloud microphysical scheme, leading to an excessive residence time of cloud water in the model (Smith et al., 2003). Unfortunately, due to the early development stage of the MC2, no final conclusion could be drawn regarding the merit of high-resolution models that work without parametrization for cumulus convection. Still, this unique experiment motivated much research activity and provided a strong stimulus to the development of non-hydrostatic models including those in several operational weather services.

More recently, Pedemonte et al. (2005) performed a broad comparison of meteorological models that issued real-time forecasts, at different centres, during the SOP. Only operational model outputs were used, and the evaluation was made against 6- and 12-hour accumulated precipitation data extracted from the MAP database. For all models, the verification was restricted to a fixed domain bounded by $43.5^{\circ}-47^{\circ} \mathrm{N}$ and $6.5^{\circ}-12.5^{\circ} \mathrm{E}$. A total of 512 stations were retained after the application of a qualitycontrol procedure. Four hydrostatic models (ECMWF, BOLAM, SM, ALADIN) and two non-hydrostatic models (MC2 and LM) were considered. The BOLAM and MC2 models were set up specifically for the MAP campaign. The ECMWF model was taken as a reference, with precipitation data sampled at $0.5^{\circ}$ resolution. BOLAM was run in Genoa (Department of Physics) and operated with two nested grids, one at $21 \mathrm{~km}$ and the other at $7 \mathrm{~km}$ resolution. The Swiss Model (SM) was operated at $14 \mathrm{~km}$ resolution at MeteoSwiss. The French model ALADIN was run in Vienna at $12 \mathrm{~km}$ resolution. The MC2 set-up has been already described above, and the LM was run with a pre-operational version at $7 \mathrm{~km}$ resolution. (For more details on the above models, including 
references and input data, see Pedemonte et al., 2005).

Figure 2 shows the frequency bias and Heidke skill score of precipitation accumulated over 6-hour intervals and evaluated for the four intervals spanning the first 24hour forecast period (day 1 ). Only day 1 forecasts are considered here, since not all the above models operated for longer (e.g. MC2). A relatively short accumulation period of 6 hours was chosen because this was more demanding on the model timing performance than a daily accumulation and also more appropriate for the mesoscale. The evaluation is made against precipitation thresholds up to $50 \mathrm{~mm}$ (6 hours $)^{-1}$, for which about 200 occurrences were observed.

The bias (Figure 2(a)) indicates that, as expected, lowresolution models (especially ECMWF) tend to have values that quickly fall below 1 (the optimum) as the threshold increases. This reflects the inability of such models to represent sharp precipitation peaks. However, the largest negative bias was obtained for the finestresolution model (MC2), related to the above-mentioned error in the microphysical scheme. In contrast, some models (LM and especially SM) tend to overestimate the spatial frequency of precipitation peaks. The effect of resolution on the bias score is exemplified by the two BOLAM scores: while at $21 \mathrm{~km}$ the bias approaches 0.5 , at $7 \mathrm{~km}$ it remains closer to 1 . ALADIN showed the most balanced behaviour in this score.

Regarding the Heidke skill score (Figure 2(b)), the spread among the different models is not as large, and values continuously decrease from about 0.5 to about 0.2 as the threshold increases. ALADIN again performs well, as does BOLAM at both resolutions (recall that
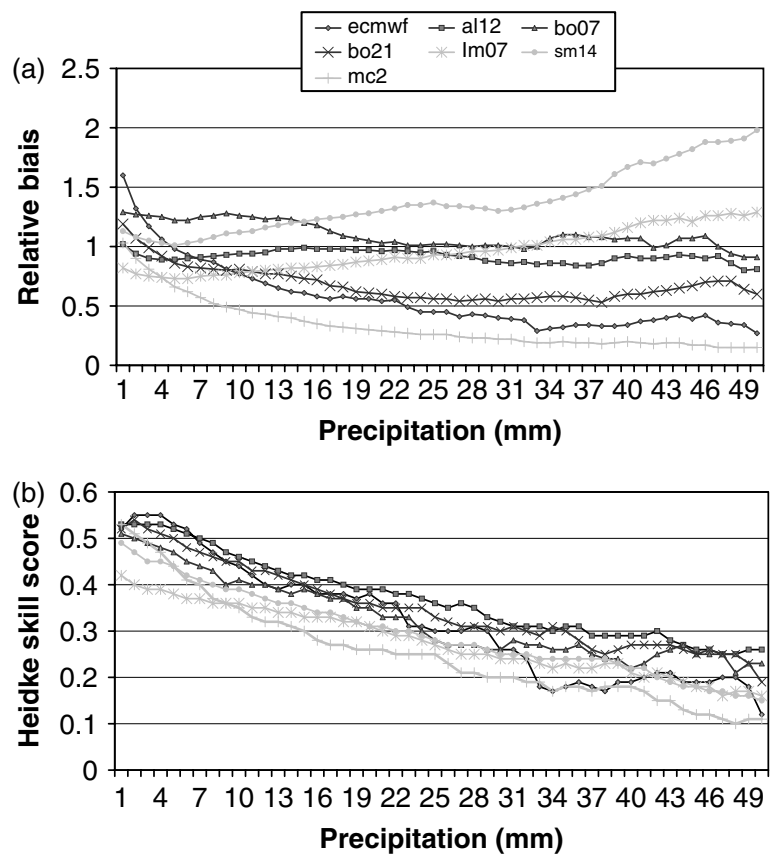

Figure 2. (a) Relative bias and (b) Heidke skill score for different operational models (ECMWF, ALADIN, BOLAM $7 \mathrm{~km}$, BOLAM $21 \mathrm{~km}$, Lokal Modell, Swiss Model, MC2 - see also Section 2(a)), operating during the MAP SOP. The abscissa indicates the observed 6-hour accumulated precipitation. there is a double penalty implied at higher resolution, see e.g. Bougeault, 2003). Note also that the ECMWF model gives the best result at low thresholds, below $7 \mathrm{~mm}(6 \mathrm{~h})^{-1}$. In summary, at the meso- $\beta$-scale, an increase in the resolution yields an increase of the precipitation and better performance for intense precipitation (i.e. above $\left.25 \mathrm{~mm}(6 \mathrm{~h})^{-1}\right)$. However, higher-resolution hydrostatic models outperformed the few non-hydrostatic models, probably also because the latter models involved in this comparison were not mature enough at the time of the MAP SOP.

Another comprehensive evaluation of model (MM5) performance based on MAP SOP is presented by Ferretti et al. (2003). Different model variables near the surface (temperature, wind, humidity) and precipitation were compared with the observations of the MAP dataset. Equitable threat scores of precipitation proved to be consistent with those of the other models discussed above.

Because of the great amount of precipitation recorded, the SOP period was also chosen as the test period for the objective verification of the probabilistic mesoscale system LEPS (developed by ARPA-SIM). Results (Tibaldi et al., 2003) indicate that LEPS scores better than the global ensemble for high precipitation thresholds.

\subsection{Case-studies}

Most of the MAP IOPs were the subject of detailed highresolution numerical studies which generally reported fairly good results in simulating precipitation.

Ferretti et al. (2003) analyzing the MM5 results obtained for IOPs $2 \mathrm{~b}, 3,5,8,10$ and 15 (with a $3 \mathrm{~km}$ grid spacing) conclude on good model precipitation skill with a better performance in mountain areas than in the Po Valley. As they were the most intense precipitating events of the SOP, IOPs $2 b$ and 8 were most extensively studied. For IOP $2 b$ (the major convective rain event of the SOP), Asencio et al. (2003, MESO-NH simulations with a grid spacing of $2.5 \mathrm{~km}$ ) or Rotunno and Ferretti (2003, MM5 simulations with a grid spacing of $3 \mathrm{~km}$ ) present quite satisfactory results, whereas Chiao et al. (2004, MM5 simulations with a grid spacing of $5 \mathrm{~km}$ ) mention good timing and location of the precipitation but an overprediction of $30 \%$, getting worse when the grid spacing was refined to $1.67 \mathrm{~km}$. However, as these three experiments were carried out with different initial conditions, and different model set-ups, no clear conclusion can be drawn regarding the benefit of the high resolution or the respective performance of the different models. In the case of IOP 8 (a long-lasting episode of widespread stratiform rain), the various simulations carried out by Rotunno and Ferretti (2003, MM5), Lin et al. (2005, MM5) or Asencio and Stein (2006, MESO-NH) have in common that they are less accurate than the IOP $2 \mathrm{~b}$ simulations and overestimate precipitation, particularly over the Apennines. Regarding the other MAP events, some very encouraging results were obtained for the IOP $2 \mathrm{a}$ (Richard et al., 2003), IOP 3 (Asencio and Stein, 2006) 
and IOP 5 (Pradier et al., 2002). All these three successfully simulated cases were associated with very narrow convective lines which cannot be resolved unless a very high resolution is used, as is evidenced by for instance Figure 14 of Pradier et al. (2002). A few other cases like IOP 15 (Buzzi et al., 2003, BOLAM simulations) or IOP 14 (Stein and Asencio, personal communication, MESO-NH simulations), both associated with a cut-off low over the Mediterranean, were not so successful and showed some substantial errors in the positioning of the precipitation already present at the large scale. However, further studies (Buzzi et al., 2004; Nuret et al., 2005), performed with refined initial conditions, showed a significant improvement in the precipitation forecasts (see Section 4.2).

In spite of the abundant activity deployed by the modelling community, no real effort has been made to systematically compare the results of the high-resolution experiments with the operational forecasts conducted during MAP and to objectively assess the potential improvement in terms of QPF. This was an additional motivation for undertaking the model intercomparison study presented in Section 6.

\section{Model improvements triggered by MAP}

The operational MC2 forecasts conducted during the MAP SOP revealed several model weaknesses which were thoroughly analyzed during the post-SOP period and triggered substantial efforts to improve the model. Besides the above-mentioned deficiency in the cloud microphysical scheme (Smith et al., 2003), the freeatmosphere temperature and wind fields were found to be heavily disturbed by grid-scale numerical noise over the Alps despite heavy smoothing of the model topography. Schär et al. (2002) suggested that numerical errors related to the terrain-following coordinate system (Gal-Chen and Somerville, 1975) were responsible for these undesirable noisy structures. These numerical errors were found to be roughly proportional to the steepness of the coordinate surfaces and to severely reduce the numerical accuracy of horizontal advection. To remedy these deficiencies, Schär et al. (2002) have developed a generalized coordinate transformation that allows for a rapid decay with height of small-scale topographic structures in the coordinate surfaces. Their so-called SLEVE (Smooth-LEvel VErtical) coordinate has been demonstrated to greatly improve the accuracy of advection over steep topography and to reduce the noisy behaviour of the MC2. Subsequently, a similar generalized coordinate system has also been developed for the pressure-based coordinate system of MM5 (Zängl, 2003), showing substantial improvements as well. Klemp et al. (2003) demonstrated that a numerically consistent implementation of the metric terms is crucial for obtaining accurate results over steep topography. In particular, they found that inconsistent metrics in the $\mathrm{MC} 2$ also contributed to the unsatisfactory flow behaviour. After these problems had been fixed, it also became possible to relax the excessive topography smoothing used in the operational MC2 set-up, which further improved the representation of mountainflow dynamics in the model. The need to reduce the topography smoothing and better preserve the mountain crest height was also identified for BOLAM by studying MAP episodes and, in particular, the lee cyclogenesis event of IOP 15 (Buzzi et al., 2003).

Another important model improvement concerns the implementation of numerical diffusion. In the majority of mesoscale models, numerical diffusion is specified as a fourth-order smoothing operator acting quasi-horizontally on the terrain-following coordinate surfaces. As was first recognized in high-resolution simulations investigating the interaction between föhn and cold-air pools, computing numerical diffusion in this way induces pronounced systematic errors over steep topography (Zängl, 2002; Zängl et al., 2004). The errors are particularly evident for temperature and moisture because these variables tend to have a strong vertical stratification. Zängl (2002) has therefore developed an improved diffusion scheme in which the numerical diffusion of temperature and moisture is evaluated truly horizontally via vertical interpolation between the adjacent coordinate surfaces. Near the surface, where a horizontal computation might intersect the ground, diffusion is still evaluated along model surfaces. However the diffusion coefficient is strongly reduced when the model grid points entering into the diffusion calculation lie at a significantly different height. The improved diffusion scheme was first implemented in MM5 and, later on, in MESO-NH. In a sensitivity study for IOP 10, Zängl (2004) demonstrated that the truly horizontal diffusion scheme could also have a significant positive impact on simulations of orographic precipitation. Indications for a beneficial impact were also found for the SLEVE coordinate, but the results were less clear than for diffusion. Finally, the MAP data were used to tune or improve the explicit microphysical schemes of some models. For example, Richard et al. (2003) and Lascaux et al. (2006) demonstrated that implementing a separate prognostic variable for hail (in addition to graupel) could be beneficial in cases of strong convection (IOP 2a).

\section{Impact of the initial and boundary conditions}

\subsection{MAP reanalysis}

A reanalysis of the entire MAP SOP was performed at ECMWF and is comprehensively described in Keil and Cardinali (2004). Compared with the ECMWF operational analysis (OPER hereafter), the MAP re-analysis (MAPRA hereafter) includes many additional data collected during the field experiment, in particular wind profiler measurements, radiosonde ascents, and numerous surface observations. It also benefits from substantial upgrades in the 4D-Var assimilation system, including an increase in the horizontal resolution (from an approximately $60 \mathrm{~km}$ mesh-size to a $40 \mathrm{~km}$ mesh size) and a 
more thorough use of satellite products. To distinguish the effects of model upgrades from those related to the use of the MAP data, a control reanalysis (CNTRL hereafter), containing only the model upgrades but no additional MAP SOP data, was simultaneously carried out.

Keil and Cardinali (2004) assessed the impact of the reanalyses on the ECMWF precipitation forecast over the whole SOP. As shown in Figure 1, the forecasts based on MAPRA show a better agreement with observations. For instance on days 8 and 40 some spurious rain present in the operational forecasts is no longer present. In the first month, forecasts from CNTRL and MAPRA are similar but, in the second half of the SOP, the impact of the additional MAP data is decisive in reducing the overestimation of the peak values of IOPs 8, 9, 10, and 14. Although the impact of the MAP reanalysis on the ECMWF precipitation forecast is not very large, it was found to be generally positive.

Compared to its availability in other large field campaigns (e.g. TOGA, FASTEX), the MAP reanalysis was available relatively shortly after the experiment and therefore was extensively used by the high-resolution modelling community, who could explore the benefit of a new and improved dataset of initial and boundary conditions. Different case-studies carried out with higherresolution models led to conclusions less definite than those obtained with the ECMWF model. The impact of MAPRA on high-resolution precipitation forecasts or hindcasts was found to be mostly weak - positive or negative - in the case of IOPs 2b, 8, 14 (MESO-NH simulations) and IOP 10 (MM5 simulations), but very positive in the case of IOP 15 (BOLAM and MOLOCH simulations), and very negative in the case of IOP $2 \mathrm{a}$ (MESO-NH simulations).

Figures 3 and 4 illustrate the impact of the reanalysis for the latter two cases. IOP 15 is characterized by the rapid development of an orographic cyclone south of the Alps and was associated with brief but intense precipitation over northern Italy (Buzzi et al., 2003; Hoinka et al., 2003). Figure 3 compares a gridded analysis of the $24 \mathrm{~h}$ accumulated rainfall at 06 UTC, 7 November 1999 with the precipitation results of two MOLOCH simulations (2.2 $\mathrm{km}$ resolution), nested in BOLAM and initialized and forced at the boundary either with OPER or MAPRA analyses. Large deviations appear between the two model fields, due solely to the different analyses. The MOLOCH run starting with MAPRA shows a much better agreement with the observations in the area close to the Adriatic coast, in the eastern portion of the domain, where rainfall in the OPER run was clearly underestimated. The model, however, in both cases overestimates precipitation in an area in the western half of the domain. The marked improvement in the MAPRA-based experiment was ascribed to a better representation of the conditionally unstable southerly flow over the Adriatic preceding the onset of the Bora wind and the subsequent strengthening of the low-level convergence over the area (Buzzi et al., 2004).
Figure 4 presents results which were obtained with MESO-NH for the case of IOP $2 \mathrm{a}$, a convective line that developed over the Alpine foothills and swept over the Lago Maggiore area (Richard et al., 2003). This event was not very intense in terms of accumulated precipitation (70 $\mathrm{mm}$ maximum), but was the most convective event observed during the whole SOP. The observations of the $12 \mathrm{~h}$ accumulated precipitation (radar-derived precipitation and rain gauge measurements) at 00 UTC 18 September 1999 are shown in Figure 4(a) and can be compared with the model results obtained from three MESO-NH simulations ( $2 \mathrm{~km}$ resolution) based upon OPER, MAPRA, and CNTRL analyses. The reference experiment initialized with OPER analysis succeeds reasonably well in reproducing the observed precipitation pattern (Figure 4(b)). However, initializing the model with MAPRA, convection is almost entirely inhibited in the simulation (Figure 4(c)). The failure of convection in this mesoscale simulation could be partly ascribed to an excessive dryness of the MAP reanalysis over the Lago Maggiore area caused by the assimilation of the wind profiler located in Lonate (via the computation of background-error standard deviation of the specific humidity; see Keil and Cardinali (2004) for further details). The use of CTRL instead of MAPRA should have palliated the problem but, as can be seen in Figure 4(d), this simulation is not as good as the reference experiment. Lascaux et al., (2004) hypothesized that a better description of the model orography in the reanalysis enhanced the blocking effect of the Apennines and weakened the convergence of the Ligurian and Adriatic flows, which sustained the convective system in the OPER-based simulation. This argument can explain the differences between the two simulations but of course does not clarify why the best results were not obtained with the supposedly best initial conditions. It is likely that the spread of the numerical simulations mainly reflects the low predictability of the IOP 2 a event (see Section 5).

\subsection{High-resolution data assimilation}

The strong sensitivity to initial conditions together with the mixed results obtained with the MAP reanalysis triggered a series of experiments aiming to assimilate mesoscale structures instead of relying entirely on the global-scale analysis to initialize high-resolution models. These experiments were based upon different methods ranging from nudging (BOLAM) to optimal interpolation (MM5, BOLAM, MESO-NH) or 3D-Var methods (MM5, MESO-NH).

In the case of IOP 2b, Faccani and Ferretti (2005) obtained a very significant improvement of the MM5 initial fields when assimilating 3-hourly surface and upperair data with a multiquadratic objective analysis. However, the impact on the precipitation forecast was weak (Ferretti and Faccani, 2005). In the case of IOP 14, Nuret et al. (2005) refined the MESO-NH initial fields by assimilating the data from the dense French surface network and obtained an improvement in the $6 \mathrm{~h}$ 
(a)

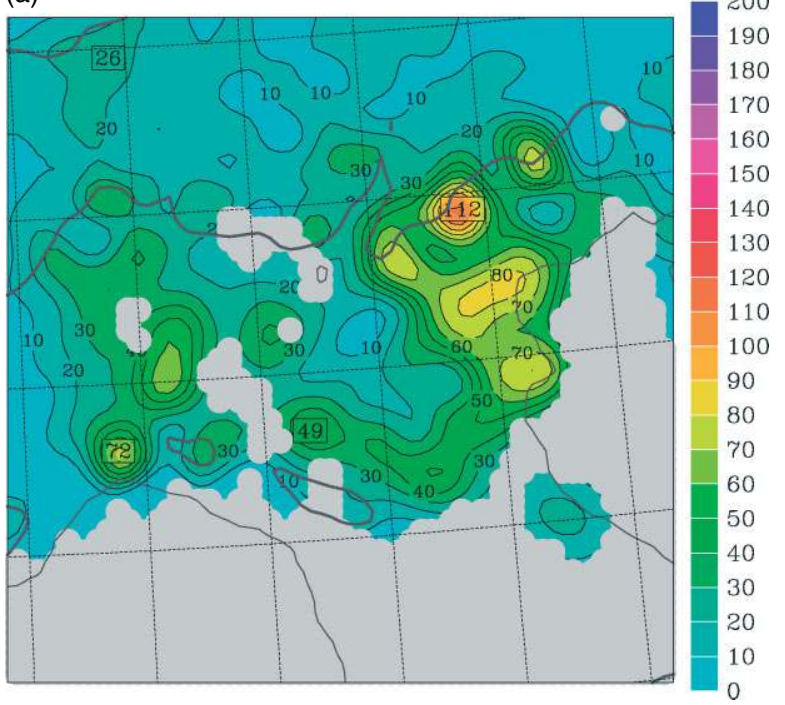

(b)

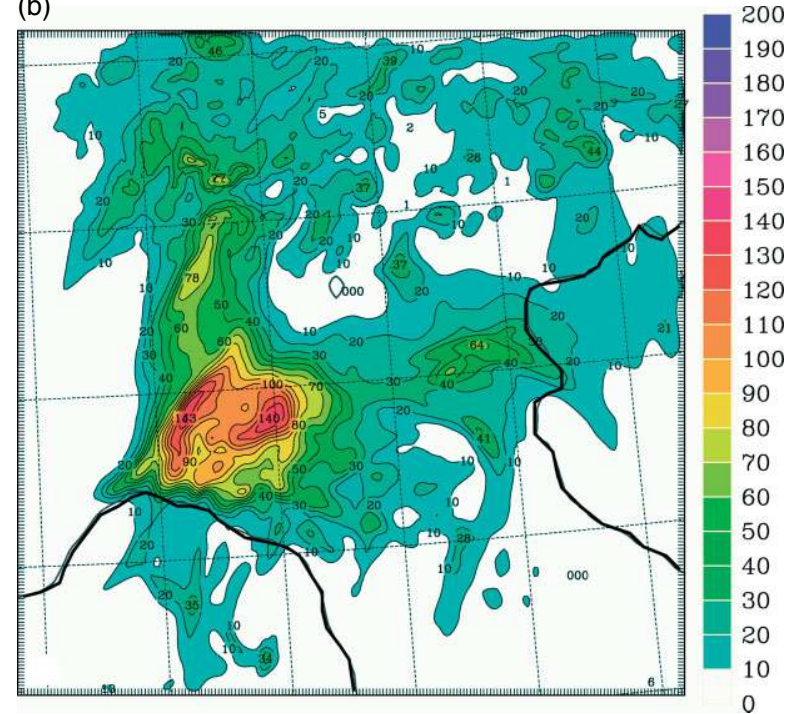

(c)

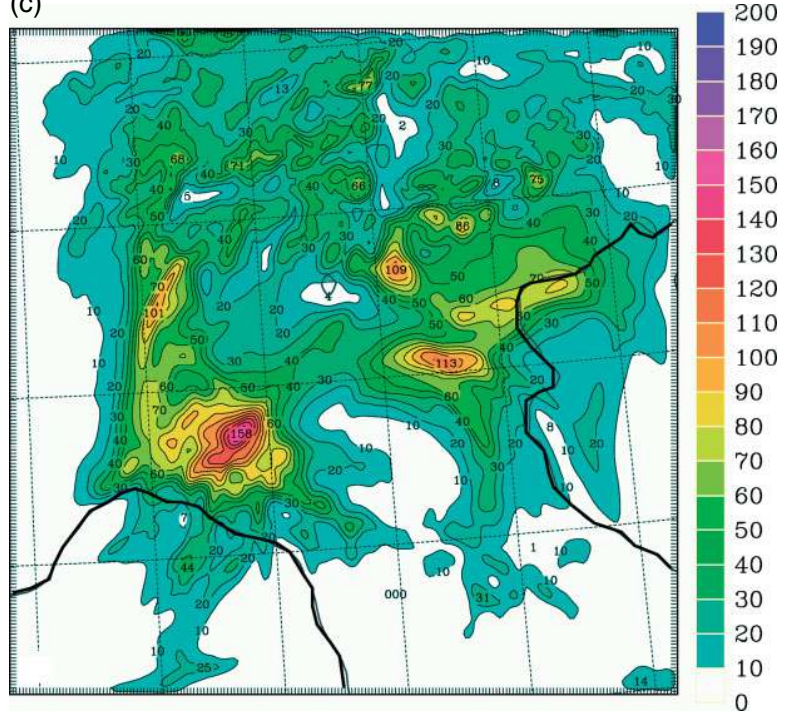

Figure 3. 24-hour accumulated rainfall (mm) at 06 UTC on 7 November 1999 (IOP 15). (a) Gridded analysis of the raingauge measurements, (b) and (c) MOLOCH simulations with a model suite based upon OPER and MAPRA analyses, respectively (from Buzzi et al., 2004).

precipitation forecast scores, persisting for at least $6 \mathrm{~h}$ and up to $18 \mathrm{~h}$. Buzzi et al. (2003) used the IOP 15 to test the impact of an optimal interpolation reanalysis, aiming at assimilating mesoscale structures. They obtained a significant overall reduction of the forecast error and a slight improvement in the precipitation fields over northern Italy.

The experiments carried out so far with 3D-Var assimilation systems either with MM5 or MESO-NH have not been completely satisfactory (e.g. Ferretti and Faccani, 2005). However, the use of these methods at the mesoscale is rather new and is probably still not well controlled. In a more experimental attempt, Davolio and Buzzi (2004) developed a nudging scheme for the assimilation of precipitation data. On the basis of an Observing System Simulation Experiment, they showed that for the IOP $2 b$, the improvement in the forecast could potentially persist up to $12 \mathrm{~h}$ after the end of the assimilation period. Numerous studies are still ongoing and the MAP database is very valuable to test the new assimilation systems, which are currently being developed in different meteorological centres (e.g. the AROME system of MétéoFrance).

\section{Forecast uncertainties, predictability, and ensemble forecasts}

Simulated precipitation sometimes appeared to be at least as sensitive to the numerical set-up of the models as to the details of their physical parametrizations. Experiments carried out with different microphysical schemes and PBL formulations available in MM5 showed only a moderate sensitivity to the physics parametrizations whereas a better numerical diffusion had a larger impact (Zängl, 2004, IOP 10). On the other hand, an ongoing study for IOP $2 b$ showed only a low sensitivity to diffusion, possibly due to stronger ambient winds and less complex topography. Another puzzling result, not 
(a)

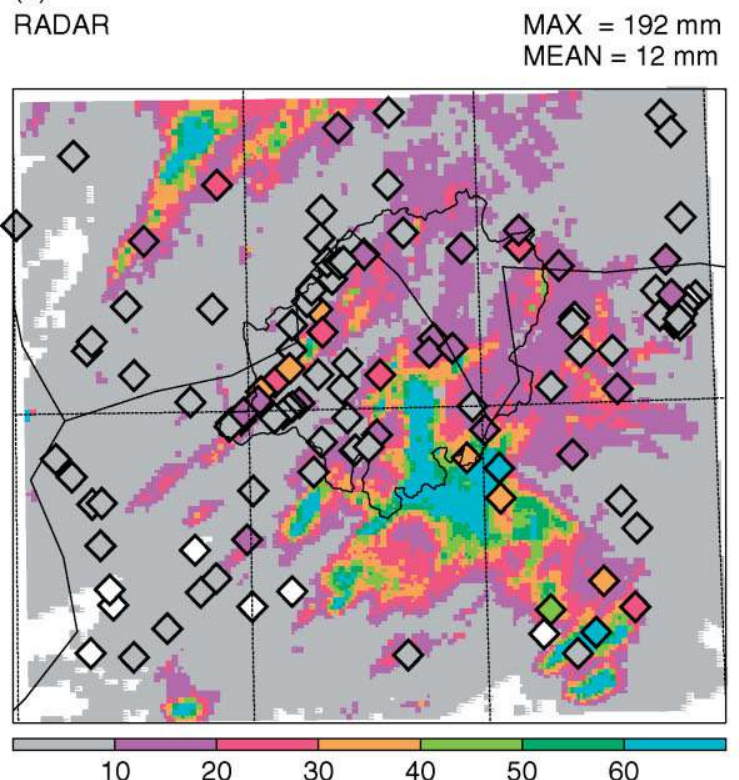

(c)
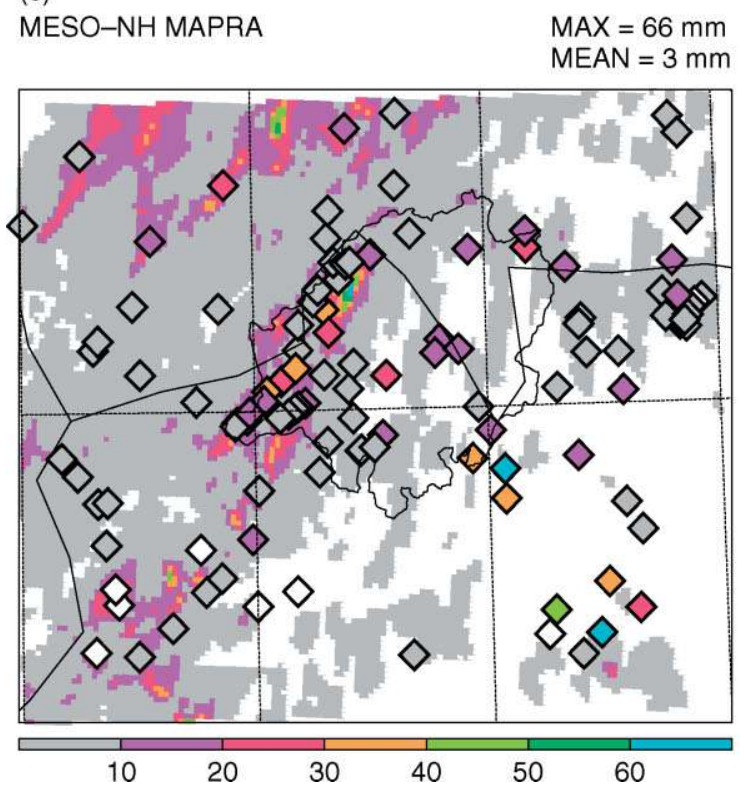

(b)

$\begin{array}{ll}\text { MESO-NH OPER } & M A X=76 \mathrm{~mm} \\ & M E A N=8 \mathrm{~mm}\end{array}$

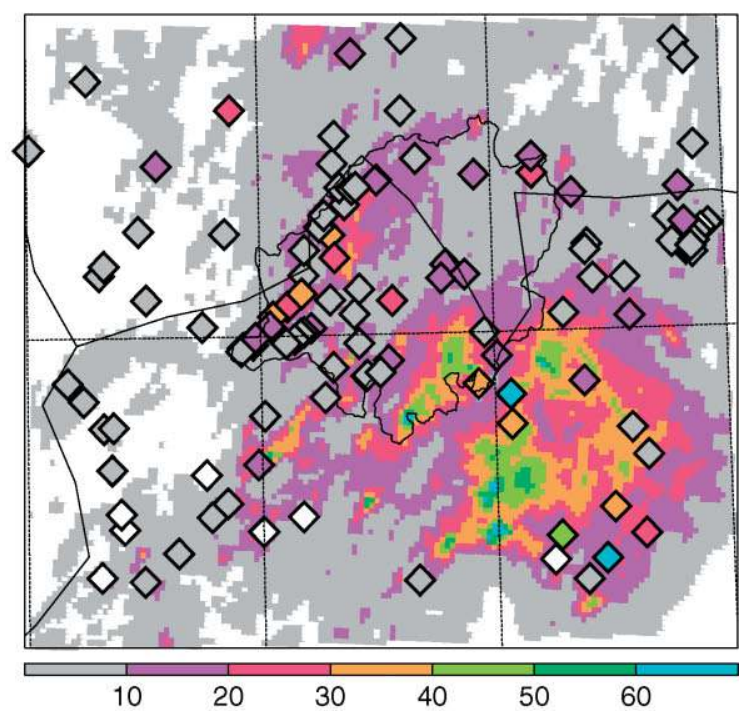

(d)
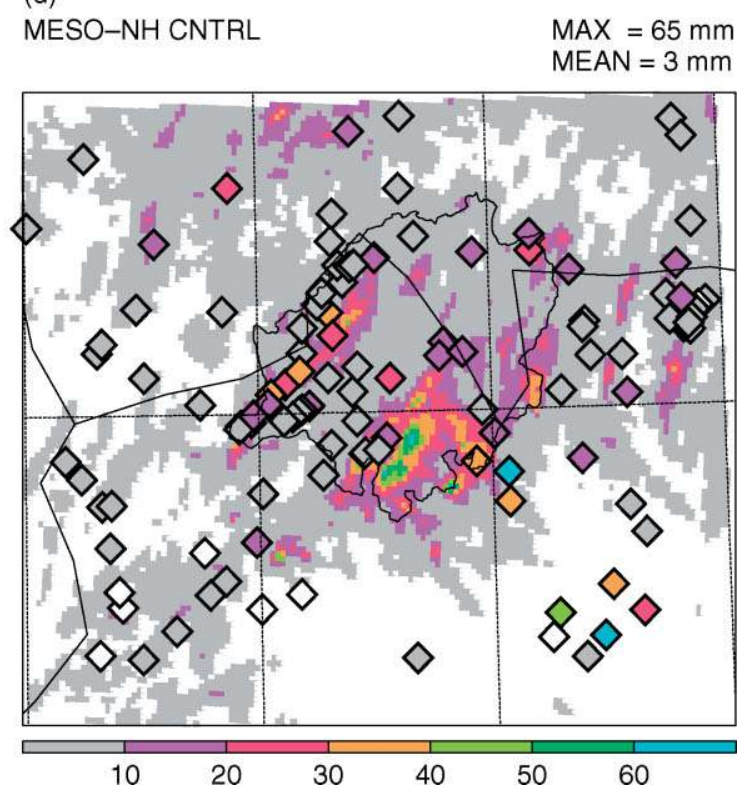

Figure 4. 12-hour accumulated rainfall (mm) at 00 UTC on 18 September 1999 (IOP 2a): (a) Radar-derived precipitation superimposed with raingauge observations (diamonds). (b), (c) and (d) MESO-NH computations with a model suite based upon OPER, MAPRA, and CNTRL analyses, respectively. The thin black lines indicate the Toce-Ticino watershed location, and the political borders between France, Switzerland, and Italy.

fully understood but reported in different MM5 studies, is a high sensitivity of the precipitation field in the fine-resolution domain to the choice of the convection scheme in the coarse-resolution domain(s) (Warner and Hsu, 2000; Zängl, 2004).

For some specific cases (IOPs 2a, 3, 15), precipitation fields were found to be extremely sensitive to the initial conditions. This was shown first by using different operational analysis systems (e.g. ECMWF versus ARPEGE) and/or confirmed later on with the use of the MAP reanalyses performed at ECMWF (MESO-NH, Asencio and Stein, personal communication; Lascaux et al., 2004; BOLAM and MOLOCH, Buzzi et al., 2004).
These results can be linked to the findings by Walser et al. (2004) or Hohenegger et al. (2006) regarding the low predictability of the IOP $2 \mathrm{a}, 3$ and 15 events. For these events, larger-scale (synoptic) errors remain very large, have a strong impact on the chronology of the precipitating event and cannot be corrected by fine-scale modelling.

Using MAP cases, two kinds of predictability study were conducted. The first one aimed at downscaling the global ECMWF ensemble prediction system (EPS), using the limited-area (LEPS) methodology. Results on four MAP cases (Marsigli et al., 2001; Molteni et al., 2001) showed the usefulness of this mesoscale ensemble 
system in the forecasting of intense precipitation events in the short-to-medium range. This led to the quasioperational implementation of the COSMO-LEPS system at ECMWF, where the LM model of the COSMO consortium is used at a resolution of $10 \mathrm{~km}$.

The second approach assumed perfect predictability on the synoptic scale to isolate the role of small-scale error growth (Walser et al., 2004; Walser and Schär, 2004). Here a convection-resolving limited-area model (the MC2 in the same set-up as in Benoit et al., 2002) was used to address the role of small-scale perturbations that may grow within the model limited domain. It was found that small-scale predictability differed strongly from case to case. The occurrence of convection alone did not necessarily limit predictability. In IOP $2 b$, individual convective cells (or the model's representation thereof) were found to be rather predictable. In contrast, for IOP 3 uncertainties (due to growth of model internal errors) prohibited the application of deterministic QPF-based approaches to hydrological forecasting (Walser and Schär, 2004), even for intermediate-size catchments. A comparison of the MC2 and LM models in convection-resolving ensemble mode further indicated that normalized spread measures were less model dependent than simulated precipitation amounts (Hohenegger et al., 2004).

\section{Model intercomparison}

Among the different precipitating events that were observed during the MAP SOP, the case of IOP $2 b$ (19-20 September 1999) was the most intense, producing local precipitation maxima exceeding $300 \mathrm{~mm}$ in less than $30 \mathrm{~h}$ in the Lago Maggiore area. Classically, the rainfall event was related to a baroclinic trough, associated with an upper-tropospheric potential vorticity anomaly, approaching the Alps from the west. Concurrently, low-level moist Mediterranean air was advected toward the Ligurian Sea and the southern flank of the Alps, the region of the Lago Maggiore target area.

Due to its strong intensity and hydrological consequences, this case was selected to intercompare the results of four different non-hydrostatic models: MM5, WRF, MOLOCH and MESO-NH. The four models were run using the same numerical protocol as far as possible. Three interactively nested domains were used with horizontal mesh sizes of 18, 6 and $2 \mathrm{~km}$, respectively. The area covered by the coarsest domain (D1) is displayed in Figure 5(a), together with the location of the nested domains (D2 and D3). The model orography of D3 (shown in Figure 5(b)) was interpolated from USGS terrain data with a $30^{\prime \prime}$ resolution and filtered such that the $2 \Delta x$ signal was entirely removed whereas $75 \%$ of the $6 \Delta x$ signal was retained, consistent with the recommendation of Davies and Brown (2001). Due to different numerical constraints, the grids of the four models were not strictly identical but differed from each other by no more than one or two grid points. The initial and boundary conditions were taken from the MAP ECMWF reanalyses (Keil and Cardinali, 2004). The initialization date was 12 UTC 19 September 1999 and the integrations were performed for 30 hours until 18 UTC 20 September 1999. In all four models, subgrid-scale convection was parametrized for horizontal resolutions of 18 and $6 \mathrm{~km}$, whereas convection was explicitly resolved in the innermost grid with a horizontal resolution of $2 \mathrm{~km}$. Cloud microphysics was treated with the Reisner-Thompson scheme in MM5 and WRF (Reisner et al., 1998; Thompson et al., 2004), which has five hydrometeor classes (cloud water and ice, rain, snow and graupel) and a two-moment scheme for cloud ice. The MOLOCH microphysics scheme is described in Drofa and Malguzzi (2004) but has recently been updated to include separate prognostic variables for graupel and hail. Information regarding the MESO-NH microphysical scheme can be found in Lascaux et al. (2006). (a)

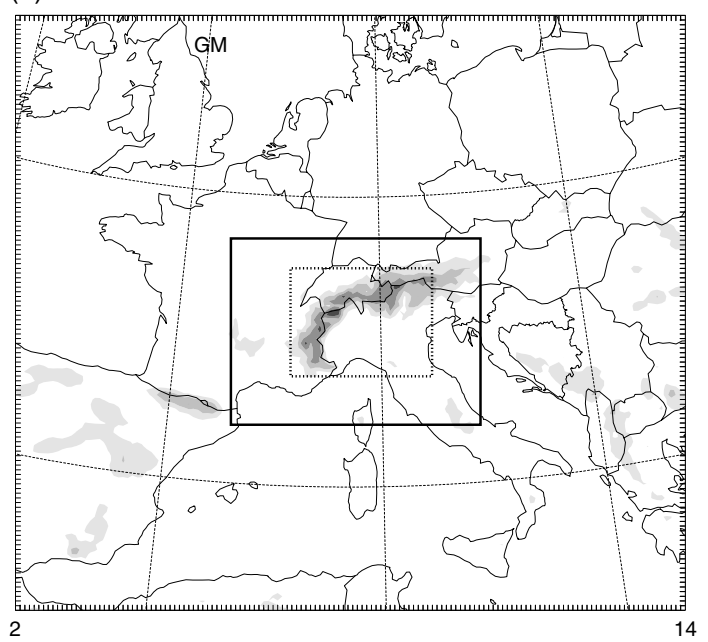

(b)

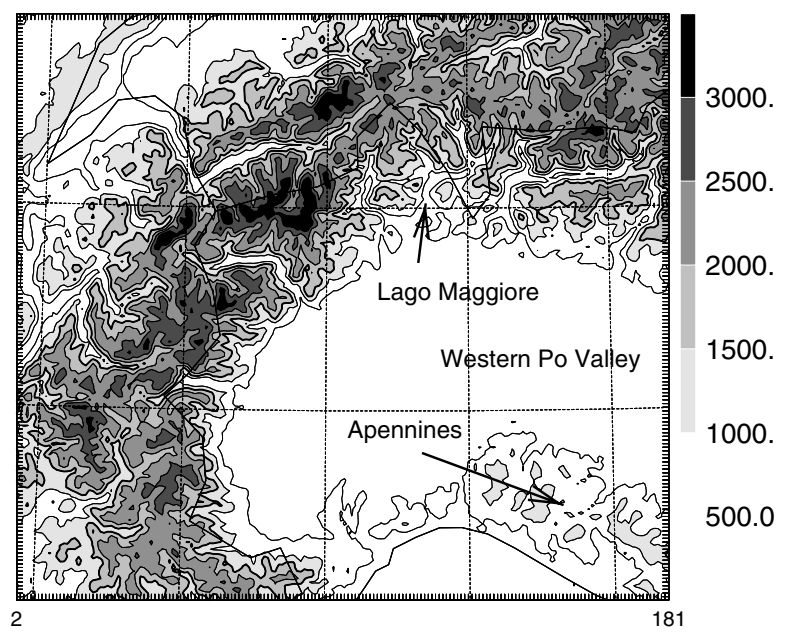

Figure 5. (a) Geographical domains used for the nested simulation. The outer frame shows the $18 \mathrm{~km}$ grid-mesh domain and its topography, and the location of the $6 \mathrm{~km}(2 \mathrm{~km})$ grid-mesh domain is indicated by a solid (dotted) box. (b) Topography (m) of the $2 \mathrm{~km}$ grid-mesh domain. 
Figure 6 compares the accumulated precipitation fields computed with the different models. The available surface observations (from 218 raingauges) are superimposed on each plot. The $27 \mathrm{~h}$ accumulation period spans from 15 UTC 19 September to 18 UTC 20 September and excludes the first 3 hours of simulation, which could be affected by model spin-up problems. There is fairly good consistency in the precipitation pattern among the four experiments. All the computations show heavy precipitation over the south-facing slopes of the Alps and of the Apennines with a pronounced maximum over the western Toce-Ticino watershed. In the western Po Valley, a comparatively dry area is clear in all simulations, reflecting a rain shadow in the lee of the Alpine arc.

(a)

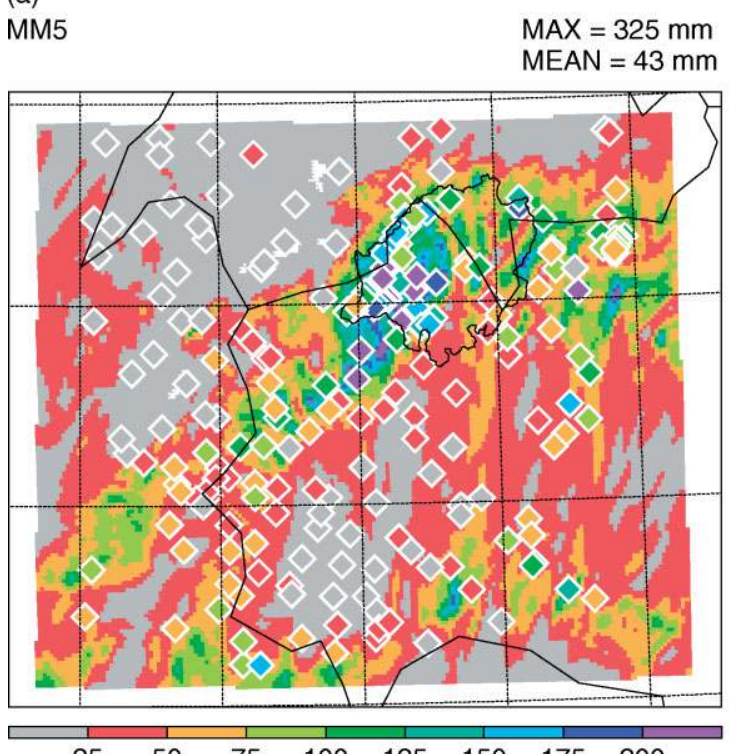

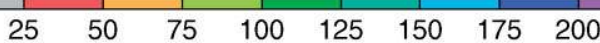

(c)
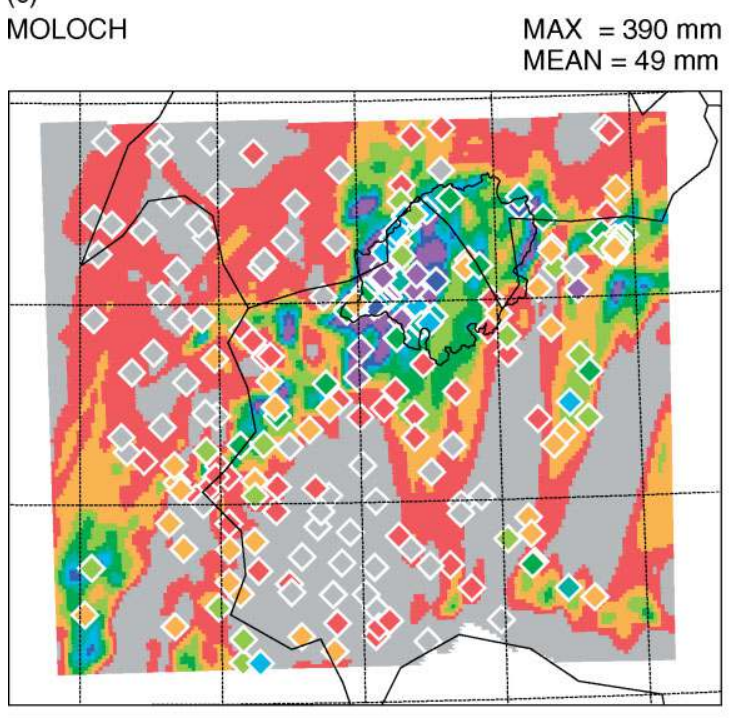

$\begin{array}{llllllll}25 & 50 & 75 & 100 & 125 & 150 & 175 & 200\end{array}$
Moderate precipitation is found over the eastern part of the Po Valley. Significant differences occur in the intensity of simulated precipitation, ranging around $10 \%$ for the domain average and reaching up to $30 \%$ for the peak intensity. The corresponding surface observations indicate that the overall pattern of simulated precipitation is quite realistic in all simulations. However, the smallscale variability in the mountainous regions is only partly reproduced in the simulations. All models but MOLOCH miss a line of heavy convective rainfall in the eastern Po Valley. North of the Alpine crest, model and observations consistently indicate a rapid decay of the rainfall.

Figure 7 provides a comparison with some operational products: the ECMWF operational forecast of 1999, the

(b)

WRF
MEAN $=312 \mathrm{~mm}$
MEAN
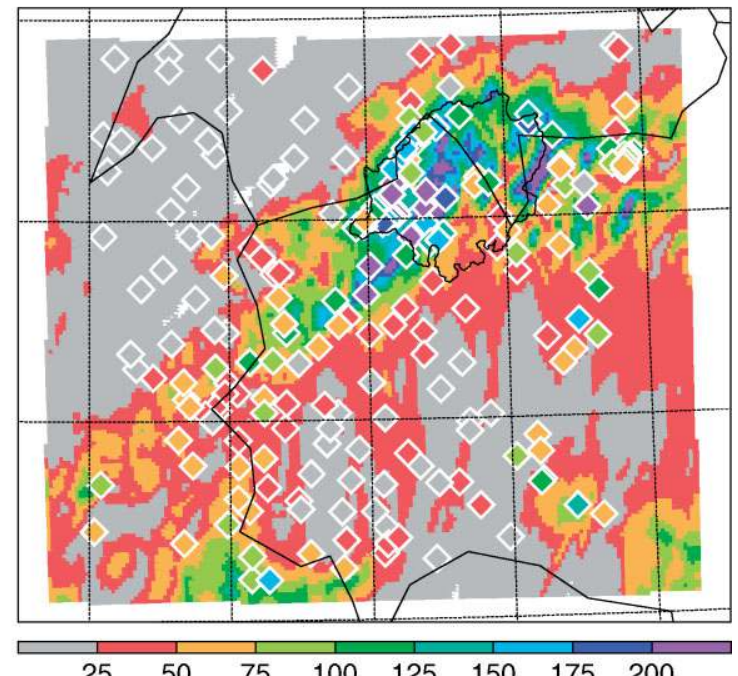

(d)

$\begin{array}{ll}\text { MESO-NH } & \text { MAX }=389 \mathrm{~mm} \\ & \text { MEAN }=46 \mathrm{~mm}\end{array}$

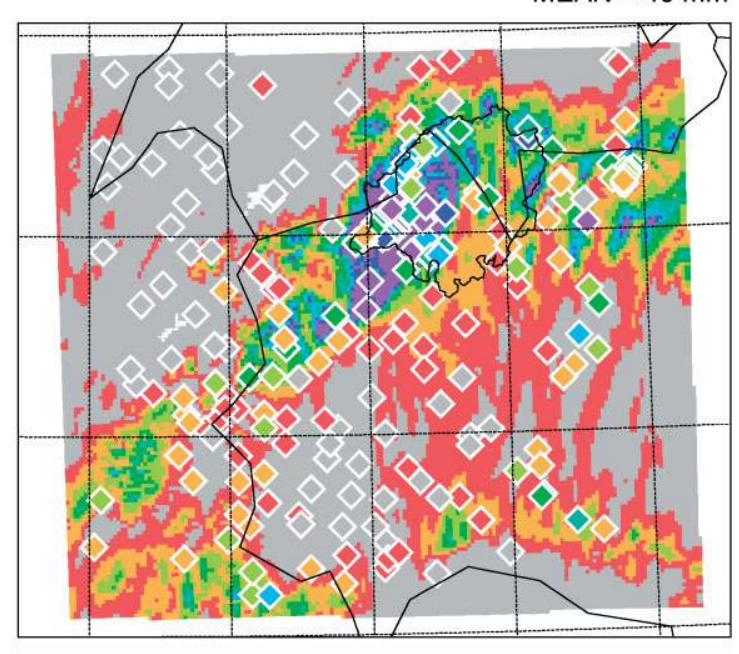

$\begin{array}{llllllll}25 & 50 & 75 & 100 & 125 & 150 & 175 & 200\end{array}$

Figure 6. Accumulated precipitation (mm) from 15 UTC on 19 September to 18 UTC on 20 September computed with (a) MM5, (b) WRF, (c) MOLOCH, and (d) MESO-NH. The maximum and domain-average values of each field are shown to the top right of each plot. The available raingauge measurements (small diamonds) are superimposed with the same colour coding. The thin black lines indicate the Toce-Ticino watershed location, and the political borders between France, Switzerland, and Italy. 
ECMWF experimental forecast initialized with the MAP reanalysis and based upon the operational model of 2002, and the French operational forecasts of 1999 from the ARPEGE global model and the ALADIN limited-area model. The horizontal resolution of the various models can be roughly estimated to be $60,40,20$ and $10 \mathrm{~km}$, respectively. Comparing Figure 6 with Figure 7, one can observe that all the operational models locate the precipitation maximum south-west of the observed maximum in the Toce-Ticino watershed. Precipitation in the Toce-Ticino area is greatly underestimated, particularly for the coarsest model resolutions. On the other hand, the coarse-resolution models tend to overestimate precipitation over most of the Po Valley. A number of reasons

(a)

$\begin{array}{ll}\text { ECMWF OPER } & \text { MAX }=98 \mathrm{~mm} \\ & M E A N=48 \mathrm{~mm}\end{array}$
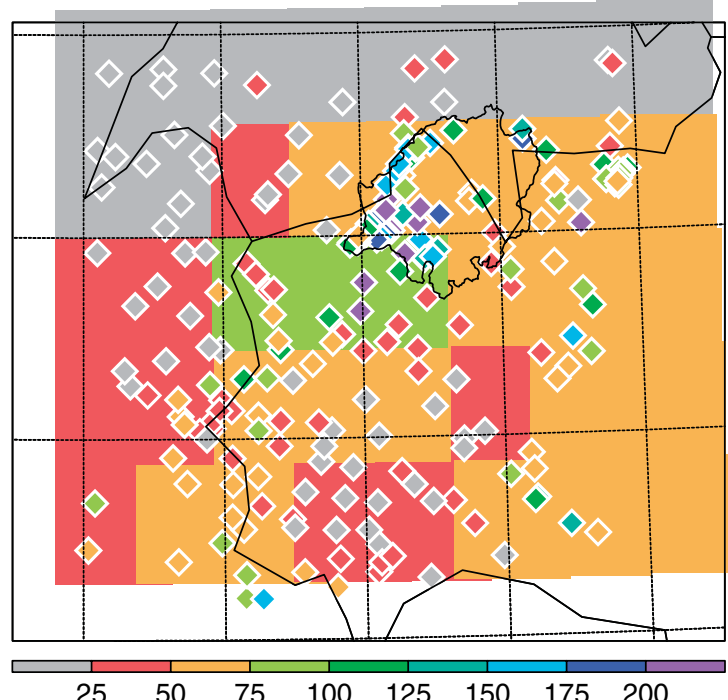

(c)

$\begin{array}{ll}\text { ARPEGE } & \text { MAX }=260 \mathrm{~mm} \\ & \text { MEAN }=65 \mathrm{~mm}\end{array}$

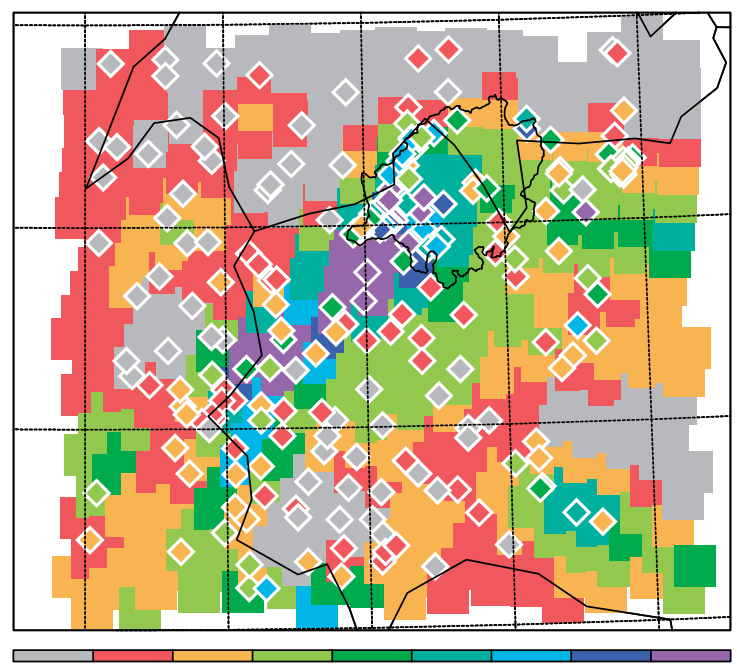

$\begin{array}{llllllll}25 & 50 & 75 & 100 & 125 & 150 & 175 & 200\end{array}$ can be suggested for these discrepancies. When the resolution is coarse, simulated orographic lifting tends to start too far upstream because of the inevitable topography smoothing. Moreover, a large fraction of the rain is usually produced by the convection parametrization in coarse-resolution models, which releases precipitation at the location where convection is triggered because parametrized convection cannot account for any drift of convective cells. Thus, a systematic windward shift can be expected even when convection is triggered at the right location. A remarkable feature is the impact of the resolution on the precipitation intensity. As expected, the maximum values become stronger when the resolution increases but this is not true for the spatial average over

(b)

$\begin{array}{ll}\text { ECMWF MAPRA } & \text { MAX }=162 \mathrm{~mm} \\ \text { MEAN }=47 \mathrm{~mm}\end{array}$
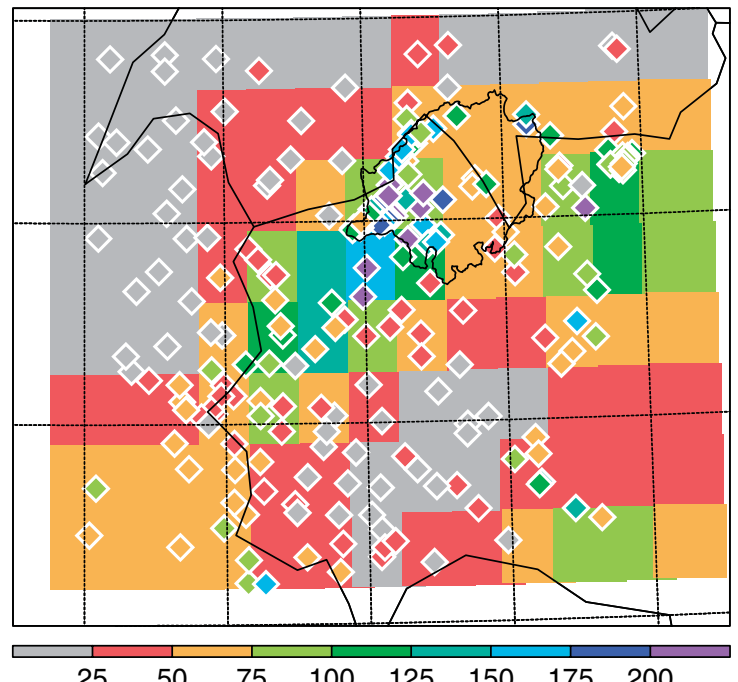

(d)

$\begin{array}{ll}\text { ALADIN } & \text { MAX }=321 \mathrm{~mm} \\ \text { MEAN }=57 \mathrm{~mm}\end{array}$

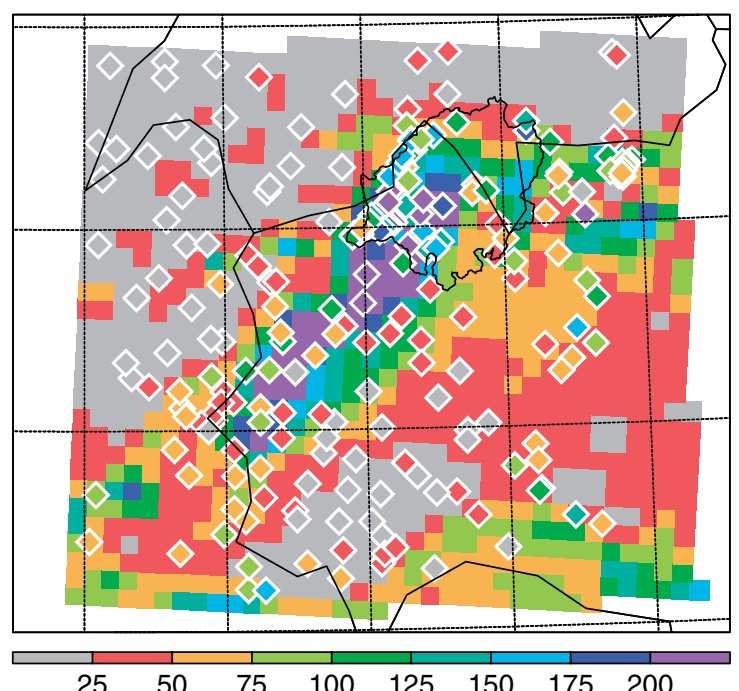

Figure 7. As Figure 6, but produced from (a) the operational ECMWF forecast, (b) the experimental ECMWF forecast, and the operational (c) ARPEGE and (d) ALADIN forecasts. 
the domain. In particular, the ARPEGE average greatly exceeds the averages of all other models, including the non-hydrostatic ones.

The visual comparison of the different precipitation plots clearly indicates that the forecasted precipitation pattern becomes more realistic as the model resolution increases. However, it does not allow the quality of the different forecasts to be evaluated quantitatively and does not support the claim that the very-high-resolution models significantly outperform the operational models. To obtain a more quantitative assessment and to score the different forecasts, standard statistics were computed after interpolating model results to the location of the observations. Figure 8 shows the different models' performance in terms of bias, root-mean-square error and correlation coefficient. All these parameters carry different information. The bias characterizes the mean error (a crucial parameter for flood forecasting) but does not measure the magnitude of the errors. The root-meansquare error (RMSE) does, but emphasizes the largest errors. Finally, the correlation measures the spatial correspondence or phase difference between the forecasts and observations without being sensitive to their absolute value.

Figure 8 reveals a number of interesting features. The bias of the different models ranges from -15 to $20 \mathrm{~mm}$ (or from $-22 \%$ to $+30 \%$ in terms of relative bias; the station-average precipitation is $69 \mathrm{~mm}$ ) and does not seem to depend in a systematic way on the model resolution. ARPEGE has the largest bias and MESO-NH the smallest one (in terms of absolute value), but the non-hydrostatic models do not necessarily have a smaller bias than the coarse-resolution operational models. However, the RMSE and particularly the correlation coefficient indicate a clear superiority of the non-hydrostatic models over the coarse-grid operational models. The nonhydrostatic models (especially MM5) have a better accuracy and a higher pattern correlation with the observed values. These results deserve to be highlighted. Most of the time, the use of standard statistics based on simple interpolation of model output to station points (as opposed to upscaling the data, as suggested for instance by Cherubini et al., 2002) is known to give lower performance for detailed high-resolution forecasts, although the fields look more realistic than for low-resolution models. This is usually explained by the fact that simulated small-scale variability matches the observed one only in a statistical sense, particularly when related to convective motion. In the present case, however, the orographic influence exerts strong control on the small-scale rainfall variability, which can be captured in a model only if the orography is sufficiently well resolved. Although the results obtained in this study are based on a small data sample, they are very encouraging for high-resolution modelling.

To better assess the differences among the nonhydrostatic models, Figure 9 presents additional sensitivity tests generated by changing parametrizations within MM5 and WRF. For MM5, the Reisner-Thompson microphysics scheme was replaced with either the simpler Reisner1 scheme (single-moment cloud ice without graupel), the Goddard scheme (includes graupel but singlemoment cloud ice; Lin et al., 1983; Tao and Simpson, 1993) or an older version of the Reisner-Thompson
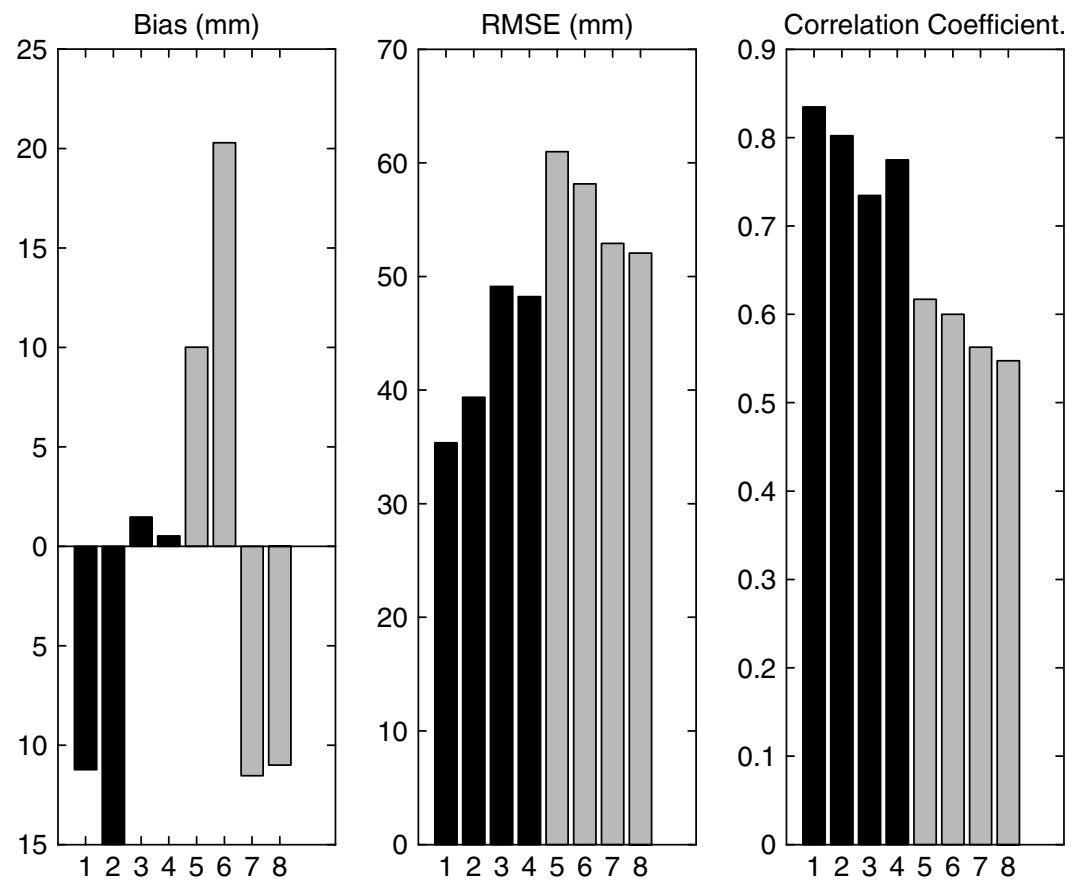

Figure 8. Bias, root-mean-square errors, and correlation coefficients between modelled and observed precipitation. The numbers on the $x$ axis refer to the different models: 1 MM5, 2 WRF, 3 MOLOCH, 4 MESO-NH, 5 ALADIN, 6 ARPEGE, 7 (operational) and 8 (experimental) ECMWF forecasts. The shading distinguishes the high-resolution research models (dark) from the low-resolution operational models (light). 

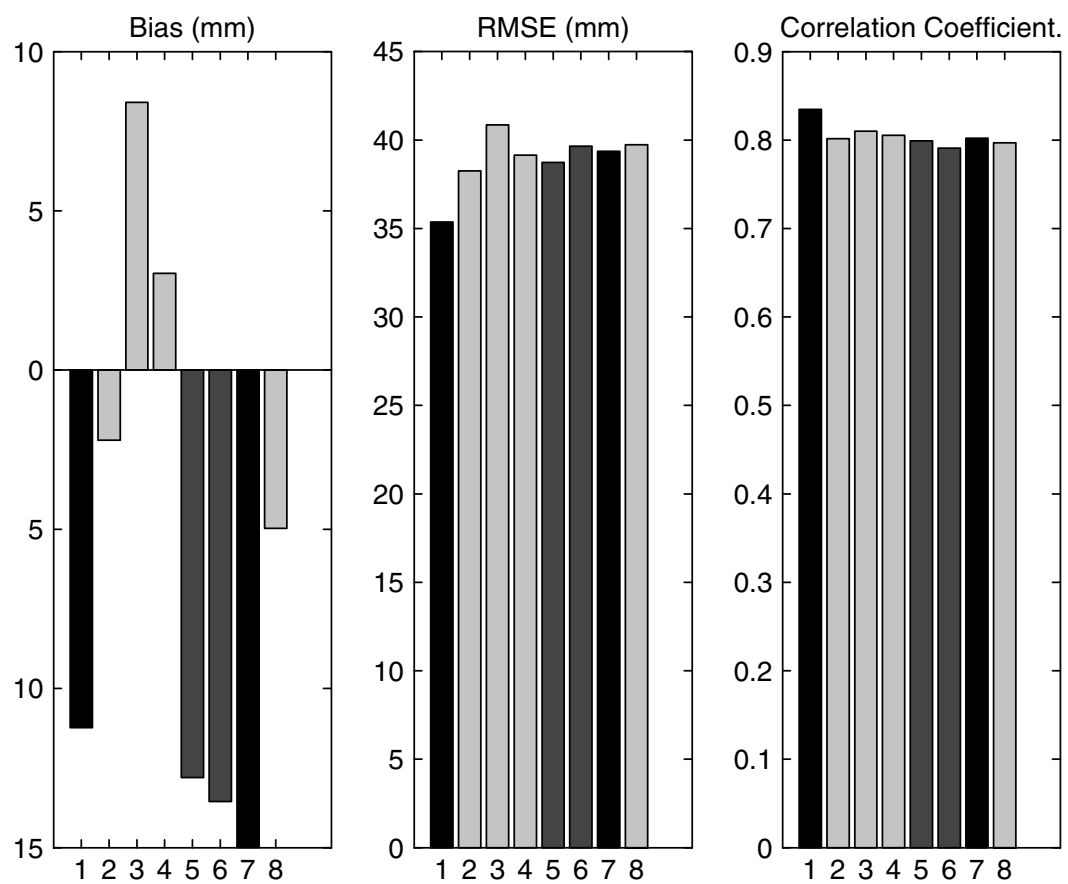

Figure 9. As Figure 8, but for MM5 and WRF sensitivity experiments with different physics parametrizations. The numbers on the $x$ axis refer to the different models: 1 MM5 reference, 2 Reisner1, 3 Goddard and 4 old Reisner2 microphysics, (5, 6) MM5 with Eta and MRF PBL scheme, respectively, and $(7,8)$ WRF reference and WSM6 microphysics (see text for further explanation).

scheme (runs 2-4 in Figure 9). Moreover, the impact of replacing the Blackadar PBL scheme (Zhang and Anthes, 1982) by the ETA scheme (Janjic, 1994) of the MRF scheme (Hong and Pan, 1996) was tested (runs 5 and 6). For WRF, the Reisner-Thompson scheme was replaced by the WSM6 scheme (Lin et al., 1983; Hong et al., 2004), which has some similarity with the MM5 Goddard scheme (runs 7 and 8). Figure 9 reveals that the impact of the microphysics scheme on the bias is at least as large as the spread between the non-hydrostatic reference experiments. In particular, the marked negative bias of the MM5 and WRF reference experiments appears to be a specific property of the Reisner-Thompson scheme, indicating that considering only one model set-up can result in misleading conclusions. This also stresses the large uncertainty still inherent in state-of-the-art cloud microphysics schemes. The RMSE and the correlation coefficient are not as good in the sensitivity tests as in the MM5 and WRF reference runs, but they remain consistently better than for Meso-NH and MOLOCH, particularly for the RMSE. The impact of the PBL scheme proved to be quite small in the case considered here, contrasting with another MAP case investigated by Zängl (2004). Also, the side effect from the vertical coordinate and the numerical diffusion scheme (not shown) turned out to be much smaller than found by Zängl (2004), which seems to be related to a higher large-scale wind speed combined with a different area of investigation that has a less complex topography. Thus, the possible impact of numerical errors appears to be comparatively small in the present case, highlighting the importance of cloud microphysics.

\section{Conclusion}

The MAP, particularly its project P1 devoted to studying orographic precipitation processes in the Alpine area, provided an ideal test-bed for assessing the performance of operational and research numerical models with respect to QPF in complex mountain areas. Forecasting precipitation is generally a highly complex task because the formation of precipitation involves interactions between many different types of processes, as synoptic-scale and mesoscale dynamics, boundary-layer processes, cloud microphysical processes etc. QPF thus depends crucially on the interplay between many different components of NWP models. Further complexity arises in mountainous topography because the dynamical forcing of precipitation needs to be adequately resolved in a model in order to obtain an accurate forecast. Moreover, orography affects dynamics and precipitation microphysics not only over the mountain slopes themselves but also at considerable distances both upstream and downstream, implying that the dynamical forcing embraces a very large scale range. This enormous complexity also renders isolating and understanding specific phenomena very difficult, so that improvements in precipitation forecasting skills have proceeded at a relatively slow pace.

The MAP dataset, comprising high-resolution raingauge data, multi-radar data, satellite data, instrumented aircraft data etc. for a variety of important weather situations, has provided a reference tool for QPF verification in recent years. The QPF evaluation of the mesoscale models operating during the MAP field phase proved to be useful in assessing the model capabilities at that time and has provided benchmarks and guidelines for 
further model development and improvements, especially for non-hydrostatic, convection-resolving models with a mesh size of a few kilometres. Progress in the formulation of a number of such models, developed at different research centres and meteorological services, was triggered by the results of MAP-related studies. The availability of global analyses assimilating MAP data, namely the MAP-Reanalysis prepared at the ECMWF, has facilitated the exploitation of MAP observations by numerical modellers.

Several findings provided by MAP case-studies and, more generally, by numerical integrations based on the MAP period and using MAP data for verification, have concerned the identification of specific relevant phenomena. These include the existence of different flow regimes associated with orographic and convective precipitation, the effects of the upstream stratification and the relative importance of the humidity distribution, interactions of cyclones and fronts with the Alpine orography, the presence of lee wave phenomena, effects of low-level wind channelling and downslope acceleration, the formation and dynamical role of potential vorticity 'streamers', at high levels, and 'banners', at low levels, etc. Such phenomena may determine the distribution and intensity of precipitation over mountains and adjacent plains. Difficulties have emerged, in particular, related to low predictability in episodes when moist convection is dominant and the sensitivity to uncertainties in the initial analyses becomes very high.

More technical aspects have been studied in relation with MAP modelling results, regarding, among others, the representation of orography, especially with respect to subgrid effects, the definition of different terrain-related coordinates, the application of diffusion operators, and the refinement of microphysical parametrizations.

Another sector of advanced research effort, aimed at improving QPF, has concerned data assimilation at different scales, but especially at high resolution, where the existing methods are more uncertain, observations are less representative (with respect to model state) and hence the impact on forecast quality is more problematic. The determination of forecast uncertainties, in this respect, has been tackled in a number of studies based on extensive tests using MAP data. Probabilistic forecast approaches have been based, for example, on LEPS methodology, on convection-resolving ensembles, based on perturbing the initial conditions on the mesoscale, and on a multimodel approach. Predictability evaluations considering the sensitivity to model characteristics and to initial conditions indicate that low predictability is usually related to the presence of convective instability. However, convective instability does not necessarily preclude predictability on temporal and spatial scales much larger than those of a convection cell when the large-scale conditions force some organization.

Finally, the results of a controlled model intercomparison, based on the MAP episode of most intense orographic precipitation on the southern flank of the Alps, have been reported. We tested four non-hydrostatic models running on the same domain and with the same horizontal $(2 \mathrm{~km})$ mesh size. The results have also been compared with those of coarser-resolution hydrostatic models. Both subjective evaluation and objective scores indicate that high-resolution models give an overall superior performance, although the scatter of results among the non-hydrostatic models is still large and proves to depend even on relatively subtle changes in dynamics and microphysics. It should be considered that all such models have undergone continuous development in recent years. Although the research effort is far from being completed, especially in the realm of data assimilation, it is possible to conclude that convective-resolving models are nowadays (almost) mature and ready to substitute or complement more traditional models for QPF forecasts on complex terrain areas. A trial effort in this respect is foreseen, on the same area of MAP (namely the large Alpine area), in the context of the MAP D-PHASE project, during summer and autumn 2007. In this project, the impact of multi-model QPF will be tested in relation to hydrological model impact and, more generally, to potential benefits for end users and society in general.

\section{Acknowledgements}

The authors would like to thank Eric Bazile, Christian Keil, Laura Pedemonte and Franck Lascaux for providing model precipitation data and/or figures for this manuscript. Thanks also go to the many MAP scientists involved in the P1 project and more especially to Nicole Asencio, Sen Chiao, Rossella Ferretti, Cathy Hohenegger, Yuh-Lang Lin, Piero Malguzzi, Chiara Marsigli, Socorro Medina, Mathieu Nuret, Christoph Schär and Hans Volkert for their comments or input.

\section{References}

Asencio N, Stein J. 2006. Origins of the reverse flow over the windward Alpine foothills during MAP IOP 3 and IOP 8. Q. J. R. Meteorol. Soc. 132: 297-316.

Asencio N, Stein J, Chong M, Gheusi F. 2003. Analysis and simulation of local and regional conditions for the rainfall over the Lago Maggiore target area during MAP IOP 2b. Q. J. R. Meteorol. Soc. 129: $565-586$.

Benoit R, Desgagné M, Pellerin P, Chartier Y, Desjardins S. 1997. The Canadian MC2: A semi-Lagrangian, semi-implicit wideband atmospheric model suited for finescale process studies and simulations. Mon. Weather Rev. 125: 2382-2415.

Benoit R, Schär C, Binder P, Chamberland S, Davies HC, Desgagné M, Girard C, Keil C, Kouwen N, Lüthi D, Maric D, Müller E, Pellerin P, Schmidli J, Schubiger F, Schwierz C, Sprenger M, Walser A, Willemse S, Yu W, Zala E. 2002. The real-time ultrafinescale forecast support during the Special Observing Period of the MAP. Bull. Am. Meteorol. Soc. 83: 85-109.

Bond NA, Mass CF, Smull BF, Houze RA, Yang M-J, Colle BA, Braun SA, Shapiro MA, Colman BR, Neiman PJ, Overland JE, Neff WD, Doyle JD. 1997. The Coastal Observation and Simulation with Topography (COAST) experiment. Bull. Am. Meteorol. Soc. 78 : 1941-1955.

Bougeault P. 2003. WMO WGNE survey of verification methods for numerical prediction of weather elements and severe weather events. Appendix C of Report of the 18th session of the CAS/JSC WGNE. http://www.wmo.ch/web/wcrp/wgnepublications.htm.

Bougeault P, Binder P, Buzzi A, Dirks R, Houze RA, Kuettner J, Smith RB, Steinacker R, Volkert H. 2001. The MAP special observing period. Bull. Am. Meteorol. Soc. 82: 433-462. 
Buzzi A, D'Isidoro M, Davolio S. 2003. A case-study of an orographic cyclone south of the Alps during the MAP SOP. Q. J. R. Meteorol. Soc. 129: 1795-1818.

Buzzi A, Davolio S, D'Isidoro M, Malguzzi P. 2004. The impact of resolution and of MAP reanalysis on the simulations of heavy precipitation during MAP cases. Meteorol. Z. 13: 91-97.

Cherubini T, Ghelli A, Lalaurette F. 2002. Verification of precipitation forecasts over the Alpine region using a high-density observing network. Weather and Forecasting 17: 238-249.

Chiao S, Lin Y-L, Kaplan ML. 2004. Numerical study of the orographic forcing of heavy precipitation during MAP IOP 2B. Mon. Weather Rev. 132: 2184-2203.

Colle BA, Mass CF, Smull BF. 1999. An observational and numerical study of a cold front interacting with the Olympic Mountains during COAST IOP 5. Mon. Weather Rev. 127: 1310-1334.

Colle BA, Mass CF, Ovens D. 2001. Evaluation of the timing and strength of MM5 and Eta surface trough passages over the eastern Pacific. Weather and Forecasting 16: 553-572.

Colle BA, Wolfe JB, Steenburgh WJ, Kingsmill DE, Cox JAW, Shafer JC. 2005. High-resolution simulations and microphysical validation of an orographic precipitation event over the Wasatch Mountains during IPEX IOP 3. Mon. Weather Rev. 133: 2947-2971.

Davies LA, Brown AR. 2001. Assessment of which scales of orography can credibly be resolved in a numerical mode. Q. J. R. Meteorol. Soc. 127: $1225-1238$.

Davolio S, Buzzi A. 2004. A nudging scheme for the assimilation of precipitation data into a mesoscale model. Weather and Forecasting 19: $855-871$.

Doms G, Schättler U. 2002. 'A description of the nonhydrostatic regional model LM. Part I: Dynamics and numerics'. Deutscher Wetterdienst, Offenbach, Germany.

Drofa O, Malguzzi P. 2004. Parameterization of microphysical processes in a non-hydrostatic prediction model. In Proceedings of 14th International Conference on Clouds and Precipitation (ICCP), Bologna, Italy.

Dudhia J. 1993. A non-hydrostatic version of the Penn State/NCAR Mesoscale Model: Validation tests and simulations of an Atlantic cyclone and cold front. Mon. Weather Rev. 121: 1493-1513.

Faccani C, Ferretti, R. 2005. Data assimilation of high density observations. I: Impact on initial conditions for the MAP/SOP IOP 2b. Q. J. R. Meteorol. Soc. 131: 21-42.

Ferretti R, Faccani C. 2005. Data assimilation of high density observations. II: Impact on the forecast of the precipitation for the MAP/SOP IOP 2b. Q. J. R. Meteorol. Soc. 131: 43-62.

Ferretti R, Paolucci T, Giuliani G, Cherubini T, Bernardini L, Visconti G. 2003. Verification of high-resolution real-time forecasts over the Alpine region during the MAP SOP. Q. J. R. Meteorol. Soc. 129: 587-607.

Fritsch JM, Houze Jr RA, Adler R, Bluestein H, Bosart L, Brown J, Carr F, Davis C, Johnson RH, Junker N, Kuo Y-H, Rutledge S, Smith J, Toth Z, Wilson JW, Zipser E, Zrnic D 1998. Quantitative precipitation forecasting: Report of the eighth prospectus development team, US Weather Research Program. Bull. Am. Meteorol. Soc. 79: 285-299.

Gal-Chen T, Somerville R. 1975. On the use of a coordinate transformation for the solution of the Navier-Stokes equations. $J$. Comput. Phys. 17: 209-228.

Hohenegger C, Schär C, Walser A, Lüthi D. 2004. 'Comparison of cloud-resolving ensemble simulations using LM and MC2 simulations'. In proceedings of 11th Conference on Mountain Meteorology, 21-25 June, Mount Washington, USA.

Hohenegger C, Lüthi D, Schär C. 2006. Predictability mysteries in cloud-resolving models. Mon. Weather Rev. 134: 2095-2107.

Hoinka KP, Richard E, Poberaj G, Busen R, Caccia J-L, Fix A, Mannstein $H$. Analysis of a potential-vorticity streamer crossing the Alps during MAP IOP 15 on 6 November 1999. Q. J. R. Meteorol. Soc. 129: 609-632.

Hong S-Y, Pan H-L. 1996. Non-local boundary layer vertical diffusion in a medium-range forecast model. Mon. Weather Rev. 124: $2322-2339$.

Hong S-Y, Dudhia J, Chen S-H. 2004. A revised approach to ice microphysical processes for the bulk parameterization of clouds and precipitation. Mon. Weather Rev. 132: 103-120.

Houze Jr RA, Medina S. 2005. Turbulence as a mechanism for orographic precipitation enhancement. J. Atmos. Sci. 62: 3599-3623.

Janjić ZI. 1994. The step-mountain eta coordinate model: Further development of the convection, viscous sublayer, and turbulent closure schemes. Mon. Weather Rev. 122: 927-945.
Keil C, Cardinali C. 2004. The ECMWF re-analysis of the Mesoscale Alpine Programme Special Observing Period. Q. J. R. Meteorol. Soc. 130: $2827-2850$

Kingsmill DE, Neiman PJ, Ralph FM, White AB. 2006. Synoptic and topographic variability of northern California precipitation characteristics in landfalling winter storms observed during CALJET. Mon. Weather Rev. 134: 2072-2094.

Klemp JB, Skamarock WC, Fuhrer O. 2003. Numerical consistency of metric terms in terrain-following coordinates. Mon. Weather Rev. 131: $1229-1239$.

Lafore JP, Stein J, Asencio N, Bougeault P, Ducrocq V, Duron J, Fisher C, Héreil P, Mascart P, Masson V, Pinty J-P, Redelsperger J-L, Richard E, Vilà-Guerau de Arellano J. 1998. The Meso-NH atmospheric simulation system. Part I: Adiabatic formulation and control simulations. Ann. Geophys. 16: 90-109.

Lascaux F, Richard E, Keil C, Bock O. 2004. Impact of the MAP reanalysis on the numerical simulation of the MAP-IOP 2A convective system. Meteorol. Z. 13: 49-54.

Lascaux F, Richard E, Pinty J-P. 2006. Numerical simulations of three different MAP IOPs and the associated microphysical processes. $Q$. J. R. Meteorol. Soc. 132: 1907-1926.

Lin Y-L, Farley RD, Orville HD. 1983. Bulk parameterization of the snow field in a cloud model. J. Climate Appl. Meteorol. 22: 1065-1092.

Lin Y-L, Reeves HD, Chen S-Y, Chiao S. 2005. Formation mechanisms for convection over the Ligurian Sea during MAP IOP 8. Mon. Weather Rev. 133: 2227-2245.

Marsigli C, Montani A, Nerozzi F, Paccagnella T, Tibaldi S, Molteni F, Buizza R. 2001. A strategy for high-resolution ensemble prediction. II: Limited-area experiments in four Alpine flood events. Q. J.R. Meteorol. Soc. 127: 2095-2115.

Mass CF, Kuo Y-H. 1998. Regional real-time numerical weather prediction: current status and future potential. Bull. Am. Meteorol. Soc. 79: 253-263.

Mass CF, Ovens D, Westrick K, Colle BA. 2002. Does increasing horizontal resolution produce more skillful forecasts? Bull. Am. Meteorol. Soc. 83: 407-430.

Medina S, Smull BF, Houze Jr. RA, Steiner M. 2005. Cross-barrier flow during orographic precipitation events: Results from MAP and IMPROVE. J. Atmos. Sci. 62: 3580-3598.

Molteni F, Buizza R, Marsigli C, Montani A, Nerozzi F, Paccagnella T. 2001. A strategy for high-resolution ensemble prediction. I: Definition of representative members and global-model experiments. Q. J. R. Meteorol. Soc. 127: 2069-2094.

Neiman PJ, Ralph FM, White AB, Kingsmill DE, Persson POG. 2002. The statistical relationship between upslope flow and rainfall in California's coastal mountains: observations during CALJET. Mon. Weather Rev. 130: 1468-1492.

Nuret M, Lafore JP, Gouget V, Ducrocq V. 2005. Mesoscale analysis and impact on simulation of the IOP 14 of the MAP experiment. $Q$. J. R. Meteorol. Soc. 131: 2769-2793.

Pedemonte L, Corazza M, Sacchetti D, Trovatore E, Buzzi A. 2005. Verification of limited-area models precipitation forecasts during the MAP SOP. Croatian Meteorol. J. 40: 268-271.

Pradier S, Chong M, Roux F. 2002. Radar observations and numerical modeling of a precipitating line during MAP IOP 5. Mon. Weather Rev. 130: 2533-2553.

Ralph FM, Persson O, Reynolds D, Nuss W, Miller D, Schmidt J, Jorgensen D, Wilczak J, Neiman P, Bao J-W, Kingsmill D, Toth Z, Velden C, White A, King C, Wurman J. 1999. 'The California Land-Falling Jets experiment (CALJET): Objectives and design of a coastal atmosphere-ocean observing system deployed during a strong El Niño'. Pp 78-81 in Preprints, 3rd AMS symposium on Integrated Observing Systems, Dallas, Texas, USA

Revell MJ, Copeland JH, Larsen HR, Wratt DS. 2002. Barrier jets around the Southern Alps of New Zealand and their potential to enhance alpine rainfall. Atmos. Res. 61: 277-298.

Reisner JR, Rasmussen RM, Bruintjes RT. 1998. Explicit forecasting of supercooled liquid water in winter storms using the MM5 mesoscale model. Q. J. R. Meteorol. Soc. 124: 1071-1107.

Richard E, Cosma S, Tabary P, Pinty J-P, Hagen M. 2003. Highresolution numerical simulations of the convective system observed in the Lago Maggiore area on the 17 September 1999 (MAP IOP 2A). $O . J . R$. Meteorol. Soc. 129: 543-564.

Rotunno R, Ferretti R. 2003. Orographic effects on rainfall in MAP cases IOP 2b and IOP 8. Q. J. R. Meteorol. Soc. 129: 373-390.

Rotunno R, Houze RA. 2007. Lessons on orographic precipitation from the Mesoscale Alpine Programme. Q. J. R. Meteorol. Soc. 133: $811-830$. 
Ryan BF, Gayet J-F. 1996. The New Zealand Southern Alps Experiment. Bull. Am. Meteorol. Soc. 77: 683-692.

Schär C, Leuenberger D, Fuhrer O, Lüthi D, Girard C. 2002. A new terrain-following vertical coordinate formulation for atmospheric prediction models. Mon. Weather Rev. 130: 2459-2480.

Shafer JC, Steenburgh WJ, Cox JAW, Monteverdi JP. 2006. Terrain influences on synoptic storm structure and mesoscale precipitation distribution during IPEX IOP 3. Mon. Weather Rev. 134: 478-497.

Schultz DM, Steenburgh WJ, Trapp RJ, Horel J, Kingsmill DE, Dunn LB, Rust WD, Cheng L, Bansemer A, Cox J, Daugherty J, Jorgensen DP, Meitín J, Showell L, Smull BF, Tarp K, Trainor M. 2002. Understanding Utah winter storms: The Intermountain Precipitation Experiment. Bull. Am. Meteorol. Soc. 83: 189-210.

Smith RB, Jiang Q, Fearon MG, Tabary P, Dorninger M, Doyle JD, Benoit R. 2003. Orographic precipitation and air mass transformation: An Alpine example. Q. J. R. Meteorol. Soc. 129: 433-454.

Stoelinga M, Hobbs PV, Mass CF, Locatelli JD, Colle BA, Houze RA, Rango AL, Bond NA, Smull BF, Rasmussen RM, Thompson G, Coleman BR. 2003. Improvement of microphysical parameterization through observational verification experiment. Bull. Am. Meteorol. Soc. 84: 1807-1826.

Tao W-K, Simpson J. 1993. Goddard cumulus ensemble model. Part I: Model description. Terr. Atmos. Oceanic Sci. 4: 35-72.

Thompson G, Rasmussen RM, Manning K. 2004. Explicit forecasts of winter precipitation using an improved bulk microphysics scheme. Part I: Description and sensitivity analysis. Mon. Weather Rev. 132: 519-542.

Tibaldi S, Paccagnella T, Marsigli C, Montani A, Nerozzi F. 2003. 'Short- to medium-range limited-area ensemble prediction: the LEPS system'. Pp 155-170 of proceedings of seminar on predictability of weather and climate, 9-13 Sep 2002. ECMWF, Reading, UK.
Volkert H, Gutermann T. 2007. Inter-domain cooperation for mesoscale atmospheric laboratories: The Mesoscale Alpine Programme as a rich study case. Q.J.R. Meteorol. Soc. 133: 949-967.

Walser A, Schär, C. 2004. Convection-resolving precipitation forecasting and its predictability in Alpine river catchments. $J$. Hydrol. 288: 57-73.

Walser A, Lüthi D, Schär C. 2004. Predictability of precipitation in a cloud-resolving model. Mon. Weather Rev. 132: 560-577.

Warner TT, Hsu H-M. 2000. Nested-model simulation of moist convection: The impact of coarse-grid parameterized convection on fine-grid resolved convection. Mon. Weather Rev. 128 2211-2231.

Zampieri M, Malguzzi P, Buzzi A. 2005. Sensitivity of quantitative precipitation forecasts to boundary-layer parameterization: A flash flood case study in the Western Mediterranean. Natural Hazard Earth System Sci. 5: 603-612.

Zängl G. 2002. An improved method for computing horizontal diffusion in a sigma-coordinate model and its application to simulations over mountainous topography. Mon. Weather Rev. 130: $1423-1432$.

Zängl G. 2003. A generalized sigma coordinate system for the MM5. Mon. Weather Rev. 131: 2875-2884.

Zängl G. 2004. The sensitivity of simulated orographic precipitation to model components other than cloud microphysics. Q. J. R. Meterol. Soc. 130: 1857-1875.

Zängl G, Chimani B, Häberli C. 2004. Numerical simulations of the föhn in the Rhine Valley on 24 October 1999 (MAP IOP 10). Mon Weather Rev. 132: 368-389.

Zhang D, Anthes RA. 1982. A high-resolution model of the planetary boundary layer - Sensitivity tests and comparisons with SESAME79 data. J. Appl. Meteorol. 21: 1594-1609. 